\title{
Why go to the British Association?
}

IN many ways the annual meeting of the British Association for the Advancement of Science, just concluded in Bath, was quite a success. There was an excellent turnout of members of the young scientists' wing of the organisation--several hundred students in the 11-to-18-ycar-old category were regular attenders at the meeting and seemed both to enjoy themselves and learn a lot. Audiences were supplemented by the usual senior contingent of enthusiasts for science, some with a professional interest in science, others keen amateurs. A wide variety of lectures was available, including, as is customary, sections on geography, sociology and economics. Symposia on broad topics such as national food requirements, science and technology for development and decision-making in science drew reasonably good crowds. The only thing missing was a reasonable turnout of the research scientists - academic, industrial and governmental-whose work the association attempts to portray.

Certainly there were nearly three hundred speakers in the four days of the meeting, and most of these were actual researchers themselves. But many of these stayed long enough to deliver their wares and no longer. The number of those actively involved in research (outside the officers of the sections) who gave the meeting four, three or even two days of their time was exceedingly small.

There are some very sound reasons for this: the meeting comes in the midst of university vacations; there are other more specialised conferences that have to be attended; there is a limit to the number of conferences any one scientist can be expected to attend, and (a circular and slightly less sound argument) there are not enough like-minded people around to warrant staying any length of time.

Of course the meeting is not a high-powered affair and there is no obvious immediate research benefit

\section{A. J. V. Gale 1895-1978}

Arthur Gale, joint Editor of Nature from 1939 to 1961 and associated with the journal since 1920, died on 4 September 1978.

Educated at Selwyn College Cambridge, he was involved in military service for most of the First World War, and was then persuaded by Sir Richard Gregory, recently appointed Editor, to join Nature as Assistant Editor. In 1939, on Gregory's retirement, the editorship passed into the joint hands of $\mathrm{Mr}$ Gale and Mr L. J. F. Brimble, who had come to Nature in 1931. Brimble continued after Gale's retirement to edit the journal single-handed until his death in 1965.

In order that Gregory and later Brimble should lead a lively public life, attending conferences, meeting scientists, championing causes, it was necessary that someone of scrupulous habits should be back in the from attendance, but are the channels by which scientist can speak to scientist across the disciplines so good elsewhere that the British Association can be ignored? For one of the most widely remarked features of science is that significant advances frequently occur when people from one discipline discover intellectual sustenance in another, maybe remote discipline. The chance to make new contacts over a period of a few days seems just the sort of 'removal of those disadvantages that impede scientific progress' which the founders of the association aimed at.

But there is another more selfless reason why research workers should attend th annual meeting more consistently-the good effect they can have on the enthusiastic young contingent. Whilst it is not necessary that every lecture delivered to the association be comprehensible to a 16-year-old, many of these young scientists would value relaxed conversations with people whom they obviously respect. Such conversations would help them understand just what it is like to be a scientist and which particular fields of study might appeal to them. The profession of research scientist is not easily understood from outside and is subject to many misapprehensions; evenings of chat in coffee bars are probably as good a way as any of dispelling illusions and clarifying ambitions.

If there was one other disappointment in the attendance at Bath it was the poor, almost negligible turnout of those who are involved in big decisions which can have a scientific content. One would have thought that many politicians, top civil servants and leading industrialists would use such an occasion to keep well informed and to sound out their constituencies. Not so. This is done in comparable assemblies in some other countries, but not in Britain. The result is a narrowmindedness and compartmentalisation that seems particularly severe in British public life.

office ensuring that the journal appeared on time each week, and that the appropriate bread and butter of Nature was attended to. This Gale did to perfection. He knew exactly what Nature was about, and he understood the science well, but his responsibility was not to comment or interpret but to ensure that other people were free to do so. He was essentially the servant of Nature and thereby of the whole scientific community.

He claimed that he only ever wrote two leaders, yet paradoxically they were at a most momentous time for science's relation with society: the two weeks following Hiroshima and Nagasaki. His calm and sensible words at that time made one regret that he did not write more often.

He married Gwendoline Veysey in 1929 and to her and to his son and daughter we send our sympathy. 